or part funding is made available to staff for further studies and conference attendance and staff recognition days. Environmental wellbeing is co-ordinated by the quality, safety and risk department and managed through an extensive organisation wide risk register supported by the quality, safety and risk committee, hygiene and infection prevention and control committee and radiation safety committee.

Result Since the formation of the Positive Working Environment Group, staff engagement in staff survey has increased from $41 \%$ in 2012 to $63 \%$ in 2016. Staff absence has decreased and staff report feeling more supported by management and peers.

Discussion By creating a co-ordinated organisation wide approach to health and wellbeing NRH has improved the working environment for staff and clients.

\section{ADDRESSING PSYCHOSOCIAL RISK FACTOR IN THE HEALTHCARE SECTOR: THE UPDATE OF INAIL METHODOLOGY WITH NEW ASSESSMENT TOOLS}

\footnotetext{
${ }^{1,2,3} \mathrm{M}$ Ronchetti, ${ }^{1,2,3} \mathrm{C}$ Di Tecco, ${ }^{1,2,3} \mathrm{C}$ Balducci, ${ }^{1,2,3} \mathrm{C}$ Consiglio, ${ }^{1,2,3} \mathrm{M}$ Ghelli, ${ }^{1,2,3}$ B Persechino, ${ }^{1,2,3}$ S lavicoli. 'INAIL - Italian Workers Compensation Authority, Department of Occupational and Environmental Medicine, Epidemiology and Hygiene; ${ }^{2}$ University of Bologna, Alma Mater Studiorum - Department of Political and Social Sciences; ${ }^{3}$ Univerity of Rome, Sapienza - Department of Psychology
}

\subsection{6/oemed-2018-ICOHabstracts.955}

Introduction Psychosocial Risk Factors was been a long-standing concerns of the healthcare sector. Several studies have shown that healthcare professionals are at an increased risk of work-related stress compared with other professionals. In Italy, according to the INSULA Survey findings, the healthcare sector was ranked first in terms of exposure to work-related stress risk. Therefore, specific approaches are needed to implement the assessment and management of psychosocial risk factors in this area.

Methods Starting from an existing methodology for the assessment and management of work related stress risk, that include a checklist (consisting of organisational indicators and work content and context factor) and a validated questionnaire (for the analysis of employees' perceptions related to seven organisational risk factors), we have identified specific topics for the health sector. Specifically, a detailed literature review has been carried out, followed by two focus groups with OSH professionals and experts of health sector, in order to identify what specific topics should be included. Subsequently, new tools were tested, involving 4 hospitals (more than 3000 workers).

Results Regarding the checklist, we have added: seven organisational indicators (eg. patients aggressions, precarious workers, ward mortality ratio) and seven work content and context factors (eg. shift work, organisational changes, procedures for managing conflicts). Among the additional scales of the questionnaire, those that reported better correlations with the preexisting ones are: work-family conflict, emotional burden, poor team integration, and defensive attitude. Additionally, four outcome variables were added: work satisfaction, turnover Intentions, emotional exhaustion and relational burnout.

Discussion Within the framework of a research project funded by the Italian Ministry of Health, the Inail methodology has been integrated with new tools in order to provide a customised path for the healthcare sector. This proposal will be made available through an online platform for data collection and analysis.

\section{KNOWLEDGE OF AND ATTITUDES TO OCCUPATIONAL HEALTH FOR HEALTHCARE WORKERS AMONG THAI PHYSICIANS}

Chatchai Ekpanyaskul* . Faculty of Medicine, Srinakharinwirot University, Bangkok, Thailand

\subsection{6/oemed-2018-ICOHabstracts.956}

Objective This study was conducted to determine the current situation regarding the level of knowledge and attitudes towards occupational health $(\mathrm{OH})$ for healthcare workers (HCWs) and related factors among Thai physicians.

Methods A cross-sectional study was conducted from 2016 to 2017 on physicians who were attending a short course on occupational medicine in Thailand. The data was collected before they studied the topic of $\mathrm{OH}$ for HCWs. The selfadministered questionnaire was used as a tool to evaluate their knowledge about and attitudes regarding $\mathrm{OH}$ for HCWs, accompanying a collection of demographic data and a set of $\mathrm{OH}$ for HCWs questions. The test included 16 closed questions including the following 4 aspects, as follows:

1. scope and responsibility of $\mathrm{OH}$ for HCWs;

2. $\mathrm{OH}$ standard and legislation;

3. occupational hazards in hospitals and

4. prevention and control.

The score for correct questions was 1 and the total score was 16. The data was presented in the form of numbers, percentages, mean and standard deviation. All of the variables were categorised into 2 groups and analysed the association by Chi-square or Fisher's exact test.

Results The response rate was 91.12\% (154 physicians). The overall mean score was $13.23 \pm 1.54$ (95\% CI: 12.99 to 13.48). The highest to lowest mean score of each aspect were as follows: prevention and control, standards and legislation, occupational hazards, scope and responsibility, respectively. The top five low proportions of knowledge and attitude were the responsibility of $\mathrm{OH}$ for $\mathrm{HCW}$, violence in hospitals, ergonomic problems, $\mathrm{OH}$ for $\mathrm{HCW}$ s were related to patient safety, the perception of hazards in hospitals, respectively. The statistical significance factors related to corrected $\mathrm{OH}$ for HCWs questions, which were as follows: the administrative work was related to the attitude of $\mathrm{OH}$ for HCWs in patient safety issues as same as their attitude to this issue about hospital accreditation.

Conclusion Most Thai physicians had good knowledge of and a positive attitude towards $\mathrm{OH}$ for HCWs. However, there are still some issues, such as $\mathrm{OH}$ duties for HCWs, working condition, the risks found in hospitals, and patient safety or hospital accreditation issues related to $\mathrm{OH}$ for HCWs needed more emphasis in occupational medicine training among Thai physicians, particularly physicians who work in administrative settings.

\section{PROFILE AND BURDEN CHRONIC DISEASE PATIENTS' CAREGIVERS FOLLOWED BY A HOMECARE SERVICE IN BRAZIL - A CROSS-SECTIONAL STUDY}

RL Fregonezi*, EWJC Neves, LR Ferreira, JG Barbosa. Centro Universitário das Faculdades Associadas de Ensino - FAE, São João da Boa Vista, Brazil

\subsection{6/oemed-2018-ICOHabstracts. 957}

Introduction Caregiver burden is a discomposure (physical, psychological, social, or financial) in dealing with person's 
disability and dependence on care. The progressive ageing of the population promoted by the demographic transition and the advent of chronic-degenerative diseases increasingly show the role of caregiver as a profession, together with the need to evaluate repercussions for their well-being and health by caring. In comparison the formal and informal caregivers, the concerns with regard to quality of life was similar. The objective of the study was to evaluate the caregiver's profile and establish a relation among the more intense burden and the degree of elderly's dependence.

Methods A descriptive cross-sectional study with 157 caregivers and 159 patients (February-September 2016) was carried out with a Preventive Medicine Program, a systematised home care service (HCS) at Unimed Health Operator, in Poços de Caldas-MG. The burden of caregivers was evaluated using Zarit Burden Interview (ZBI); to evaluate self-care capacity, the Palliative Performance Scale (PPS) was applied. Statistical analysis was performed using the Mann-Whitney test, using $\mathrm{p}<0.05$.

Results Patients were divided in 2 groups $(87 \%$ PPS $<60$, $13 \%$ PPS $>60$, average PPS $=48.89$ ), demonstrating that most patients were highly care dependent. $42,5 \%$ of the caregivers have moderate-intense burden for the more dependent patient's group with PPS $\leq 60$ compared to only $2.5 \%$ with moderate burden in less dependent group of patients with PPS $>60 \quad(\mathrm{p}<0,001)$. Average $\mathrm{ZBI}=46.36$; Impact on care $=40 \%$; Interpersonal relationship $=32 \%$; Expectation with care $=61 \%$; Perceived self-efficacy $=51 \%$. Caregiver profile: mostly female (mean age $=58$ years-old); the burden is only influenced by the level of dependency of the patient $(\mathrm{p}<0,001)$.

Discussion There is a moderate-severe burden for caregiver's patients assisted by Unimed's HCS, and this was directly related to the level of dependence measured by PPS. These data is in accordance to a Portuguese study, which identified a moderate-intense burden in $37.2 \%$ of the caregivers.

\section{REPORTING OCCUPATIONAL BLOOD EXPOSURES: DOES IT RELATE TO OUR KNOWLEDGE ON TRANSMISSION RISKS?}

${ }^{1}$ A Jones*, ${ }^{2}$ B Hayes. 'Specialist Registrar in Occupational Medicine, Beaumont Hospital, Dublin, Ireland; ${ }^{2}$ Consultant Occupational Physician, Beaumont Hospital, Dublin, Ireland

\subsection{6/oemed-2018-ICOHabstracts.958}

Introduction Occupational Blood Exposures (OBEs) are a significant occupational hazard in the healthcare sector. This study aimed to assess the practice of reporting OBEs among healthcare workers (HCWs), namely doctors, nurses and healthcare assistants (HCAs), and if there is a difference in the reporting practice between these groups. Whether a HCWs knowledge of the risks associated with an OBE, such as the risk of transmission of various blood borne viruses, has an influence on their likelihood to report an OBE was also considered.

Methods A questionnaire was distributed to all Non-Consultant Hospital Doctors (NCHDs), all nurses and all HCAs working in a large tertiary hospital. The survey was in both paper and electronic format. It assessed both the individuals past exposures and knowledge of the associated risks.

Results Of the study participants, 25.4\% were doctors, $63.3 \%$ were nurses and $11.2 \%$ were HCAs. $17.8 \%$ had experienced an OBE in the previous 12 months. Doctors accounted for the largest group, with $42 \%$ having a recent exposure. Doctors were also significantly less likely than their nursing and HCA colleagues to report an OBE, with $73.9 \%$ having an unreported exposure in the previous 12 months.

Two of four questions assessing the healthcare workers knowledge of the risks of OBEs showed a statistically significant difference in the knowledge across the three groups, with both doctors and nurses displaying a greater knowledge than HCA's.

Discussion The true prevalence of OBEs in healthcare workers is likely significantly higher than reported. The main reasons identified for not reporting exposures were due to the HCW risk assessing the injury themselves, and deeming it not significant. This study supports the hypothesis that there is a relationship between the knowledge a HCW has on the risks associated with OBE's and their likelihood to report an exposure, however further research is required in order to quantify the magnitude of this relationship.

\section{MANAGEMENT OF OCCUPATIONAL RISKS IN HOSPITALS: CASE OF CHR - ATAKPAMÉ (TOGO)}

${ }^{1} \mathrm{~K}$ Kara-Peketii, ${ }^{1}$ YA Agbobli, ${ }^{2} \mathrm{~F}$ Pandao. ${ }^{1}$ University of Lomé (TOGO); ${ }^{2}$ Pôle santé travail environnement et recherche (TOGO)

\subsection{6/oemed-2018-ICOHabstracts.959}

Introduction The hospital is a multi-risk workplace. To the risk of any organisational structure are added those linked to the essence of its activity: the presence of pathogens, the use of sensitive technologies or devices, the coexistence of stress, suffering and death.

Methods This is a prospective study that took place from December 18, 2015 to march 18, 2016. It is part of occupational safety and health.

Results The approach to psycho-social risk management at CHR Atakpamé shows that the staff of this hospital is exposed primarily to biological, mechanical hazards, particularly blood exposition accident, ergonomic risk, and stress. They are also exposed to other risks related to postures, noise, lighting and thermal environments.

Discussion More than 61\% of CHR Atakpamé staff felt that they did not have access to occupational hazard information; $86 \%$ stated that they did not have a good knowledge of institutional procedures related to occupational accidents and diseases. $36 \%$ of the staff reported their occupational accidents and only $2 \%$ of them were recognised. However, of the $46 \%$ professional diseases reported none had been recognised.

In Ben Rahal's study, out of 10 reported occupational accidents, only one was recognised due to a lack of information on the reporting procedure.

\section{CHEST X-RAY SCREENING FOR PRE-EMPLOYED HEALTHCARE WORKERS IN A PRIVATE HOSPITAL, THAILAND}

Worrapan Karnjanakantorn. Bangkok Hospital Group

\subsection{6/oemed-2018-ICOHabstracts.960}

Background Thailand is classified by WHO as one of the 22 countries in the world with the highest TB burden. With a 